\title{
Preparation and characterization of a coacervate extended-release microparticulate delivery system for Lactobacillus rhamnosus
}

This article was published in the following Dove Press journal:

International Journal of Nanomedicine

23 August 201I

Number of times this article has been viewed

\author{
Sk Md Athar Alli \\ Department of Pharmaceutical \\ Technology, Jadavpur University, \\ Kolkata, West Bengal, India
}

Correspondence: Sk Md Athar Alli Department of Pharmacy, VBS Purvanchal University, Jaunpur 222 00I, Uttar Pradesh, India

Tel +9l 5452252567

Fax +91 5452252567

Email smatharalli@gmail.com
Background: The purpose of this study was to develop a mucoadhesive coacervate microparticulate system to deliver viable Lactobacillus rhamnosus cells into the gut for an extended period of time while maintaining high numbers of viable cells within the formulation throughout its shelf-life and during gastrointestinal transit.

Methods: Core coacervate mucoadhesive microparticles of L. rhamnosus were developed using several grades of hypromellose and were subsequently enteric-coated with hypromellose phthalate. Microparticles were evaluated for percent yield, entrapment efficiency, surface morphology, particle size, size distribution, zeta potential, flow properties, in vitro swelling, mucoadhesion properties, in vitro release profile and release kinetics, in vivo probiotic activity, and stability. The values for the kinetic constant and release exponent of model-dependent approaches, the difference factor, similarity factor, and Rescigno indices of model-independent approaches were determined for analyzing in vitro dissolution profiles.

Results: Experimental microparticles of formulation batches were of spherical shape with percent yields of $41.24 \%-58.18 \%$, entrapment efficiency $45.18 \%-64.16 \%$, mean particle size $33.10-49.62 \mu \mathrm{m}$, and zeta potential around $-11.5 \mathrm{mV}$, confirming adequate stability of L. rhamnosus at room temperature. The in vitro L. rhamnosus release profile follows zeroorder kinetics and depends on the grade of hypromellose and the L. rhamnosus to hypromellose ratio.

Conclusion: Microparticles delivered L. rhamnosus in simulated intestinal conditions for an extended period, following zero-order kinetics, and exhibited appreciable mucoadhesion in simulated intestinal conditions.

Keywords: Lactobacillus rhamnosus, mucoadhesive, microparticles, extended-release, intestine

\section{Introduction}

Intake of viable Lactobacillus rhamnosus $(L R)$ cells, at around $10^{7} \mathrm{cfu},{ }^{1,2}$ aids in the prevention of intestinal tract illnesses, ${ }^{3}$ suppresses bacterial infection in renal patients, ${ }^{4}$ safeguards the urogenital tract by excreting biosurfactants, ${ }^{5}$ stimulates antibody production, aids the immune system, assists the phagocytic process, helps the body to combat dangerous invasive bacteria, controls food-associated allergic inflammation, ${ }^{6}$ shortens the duration of diarrhea associated with rotavirus infection, ${ }^{7}$ and reduces use of antibiotics to treat Helicobacter pylori infection. ${ }^{8}$

Reported therapeutic benefits are associated with the ability of $L R$ to secret coagulin, a bacteriocin, which is active against a broad spectrum of enteric microbes. ${ }^{1} L R$ is well tolerated with very rare side effects, and its regular intake can 
be effective in supplementing and maintaining digestive tract health. Processing conditions during formulation and noncompliance with storage requirements during shipment and storage result in loss of cell viability in the dosage formulation. Acidic conditions in the stomach, various hydrolytic enzymes, and bile salts in the gastrointestinal tract also adversely affect the viability of $L R$ after ingestion. ${ }^{9-14}$

Nowadays, microparticulate systems have been exploited, not only to reduce loss of cell viability during storage and transport, but also to improve and maintain viable cells arriving in the intestine..$^{9-11}$ Decreased performance of microparticles is attributable to their short gastric retention time, a physiological limitation which can be improved by coupling mucoadhesion properties to the microparticles through developing mucoadhesive microparticles which will in turn simultaneously improve gastric retention time and bioavailability. ${ }^{15-17}$ Hypromellose and hypromellose phthalate are safe for human consumption, and because of the good mucoadhesive and release rate-controlling properties of hypromellose, it is preferred in mucoadhesive formulations. ${ }^{16-19}$ These observations indicate a strong need to develop a dosage form that will deliver $L R$ into the gut with improved gastric retention time and adequate stability during storage and gastrointestinal transit, which can be achieved with extended-release mucoadhesive microparticles.

\section{Materials and methods Materials}

Freeze-dried $L R$ R0011-150 powder was donated by Cipla Limited (Mumbai, India). Hypromellose phthalate (HP-50) was donated by Glenmark Pharmaceuticals Limited (Nasik, India). Different grades of hypromellose, ie, Methocel E5 Premium LV (E5), Methocel E50 Premium LV (E50), and Methocel E10 M Premium CR (E10 M), were donated by Indoco Remedies Limited (Mumbai, India). DeMann Rogosa Sharpe agar media and other analytical grade laboratory chemicals were purchased from HiMedia Laboratories Limited (Mumbai, India).

\section{In-house $L R$ specification compliance test}

A number of cell count tests (bacteriological, total aerobic bacteria, coliforms, enterobacteriaceae, other Gram-negative bacteria, yeast, molds), and tests to ensure the absence of contaminants (Escherichia coli, Staphylococcus aureus, and Salmonella), were performed as a compliance to the specifications of the certificate of analysis.

\section{Preparation of mucoadhesive microparticles}

Core mucoadhesive microparticles of $L R$ were prepared aseptically with hypromellose employing coacervation and phase separation technique. ${ }^{16,20}$ Hypromellose $5 \mathrm{~g}$ was dissolved in $200 \mathrm{~mL}$ of cold deionized water $\left(4^{\circ} \mathrm{C} \pm 2^{\circ} \mathrm{C}\right)$. Polysorbate- $802 \mathrm{~g}$ was dissolved in this solution under stirring, followed by aseptic filtration using a $0.45 \mu \mathrm{m}$ PVDF filter membrane (Millipore Corporation, Bedford, MA). A calculated quantity of $L R$ was dispersed in the above solution, sonicated at $20 \mathrm{kHz}$ for 1 minute, and the temperature was raised gradually up to $30^{\circ} \mathrm{C} \pm 2^{\circ} \mathrm{C}$ with stirring at $500 \pm 25 \mathrm{rpm}$ for 30 minutes. Acetone $50 \mathrm{~mL}$ was added dropwise under stirring and stirred for a further 10 minutes. Microparticles were collected by aseptic filtration of the dispersion with a $10 \mu \mathrm{m}$ nylon filter (Millipore Corporation), followed by washing three times with sterile water for injection $\left(30^{\circ} \mathrm{C} \pm 2^{\circ} \mathrm{C}\right)$ and kept in a desiccator for 24 hours. All formulation batches having the composition described in Table 1 were prepared in triplicate. Aseptic processing was carried out on the bench using a horizontal laminar flow clean air work station (1500048-24-24, Klenzaids Bioclean Devices Ltd, Mumbai, India). ${ }^{16,20}$

\section{Coating of microparticles}

HP-50 solution $200 \mathrm{~mL}(10 \% \mathrm{w} / \mathrm{w})$ was prepared with phosphate buffer ${ }^{21}$ at $\mathrm{pH} 6.8$, and polyethylene glycol 200 $4 \mathrm{~g}$ and polysorbate- $802 \mathrm{~g}$ was dissolved in it. The solution was filtered aseptically using a $0.45 \mu \mathrm{m}$ PVDF filter membrane followed by dispersing tare core microparticles in it under stirring at $300 \pm 25 \mathrm{rpm}$, and then $40 \mathrm{~mL}$ of propan-2-ol was added dropwise. Stirring was continued for 30 minutes, then the coated microparticles were separated by aseptic filtration, washed three times with sterile water for injection $\left(30^{\circ} \mathrm{C} \pm 2^{\circ} \mathrm{C}\right)$, and kept in a desiccator for 24 hours, followed by determination of the final weight, aseptically packed in glass vials, and stored in a refrigerator for further use.

\section{Coating stage percent weight gain}

From the tare weight $\left(W_{I}\right)$ of the dried core microparticles that had been subjected to coating and the tare weight $\left(W_{F}\right)$ of the dried coated microparticles, the coating stage percent weight gain value was determined using equation 1 .

Coating stage percent weight gain $(\% \mathrm{w} / \mathrm{w})$

$$
=\frac{W_{F}-W_{I}}{W_{I}} \times 100
$$


Table I Formulation formulae and values of evaluation parameters of all formulation batches

\begin{tabular}{|c|c|c|c|c|c|c|}
\hline $\begin{array}{l}\text { Formulation codel } \\
\text { parameter }\end{array}$ & $\mathbf{F I}$ & $\mathbf{F 2}$ & $\mathbf{F 3}$ & $\mathbf{F 4}$ & $\mathbf{F 5}$ & F6 \\
\hline Grade of Methocel Premium used & E5-LV & E5-LV & EI5-LV & EI5-LV & EIOM-CR & EIOM-CR \\
\hline Lactobacillus rhamnosus to polymer ratio & $\mathrm{I}: \mathrm{I}$ & $\mathrm{I}: 2$ & $\mathrm{I}: 1$ & $\mathrm{I}: 2$ & $\mathrm{I}: \mathrm{I}$ & $\mathrm{I}: 2$ \\
\hline Percent yield $(w / w)^{a}$ & $58.18 \pm 1.98$ & $49.21 \pm 1.89$ & $54.91 \pm 1.86$ & $45.46 \pm 1.63$ & $49.32 \pm 1.83$ & $41.24 \pm 1.76$ \\
\hline Entrapment efficiency $(\% \mathrm{cfu} / \mathrm{g})^{\mathrm{a}}$ & $64.16 \pm 1.53$ & $57.25 \pm 1.81$ & $58.42 \pm 1.96$ & $52.62 \pm 1.79$ & $51.84 \pm 1.86$ & $45.18 \pm 1.73$ \\
\hline Mean particle size $(\mu \mathrm{m})^{\mathrm{a}}$ & $33.10 \pm 1.32$ & $35.90 \pm 1.53$ & $36.45 \pm 1.58$ & $44.23 \pm 1.96$ & $46.32 \pm 2.02$ & $49.62 \pm 1.87$ \\
\hline \multicolumn{7}{|l|}{ Zeta potential $(\mathrm{mV})^{\mathrm{a}}$} \\
\hline Uncoated microparticles & $-19.2 \pm 0.3$ & $-19.1 \pm 0.5$ & $-19.3 \pm 0.7$ & $-19.4 \pm 0.4$ & $-18.9 \pm 0.9$ & $-19.3 \pm 0.8$ \\
\hline Coated microparticles & $-11.6 \pm 0.3$ & $-11.6 \pm 0.8$ & $-11.4 \pm 0.9$ & $-11.3 \pm 0.6$ & $-11.8 \pm 0.6$ & $-11.2 \pm 0.7$ \\
\hline Percent swelling ${ }^{\mathrm{a}}$ & $1.38 \pm 0.049$ & $1.24 \pm 0.046$ & $1.13 \pm 0.039$ & $1.03 \pm 0.043$ & $0.88 \pm 0.038$ & $0.82 \pm 0.031$ \\
\hline Percent adhesive strength ${ }^{\mathrm{a}}$ & $73.36 \pm 1.32$ & $68.86 \pm 1.53$ & $62.64 \pm 1.71$ & $55.51 \pm 1.46$ & $48.71 \pm 1.34$ & $42.61 \pm 1.42$ \\
\hline Percent mucoadhesion ${ }^{\mathrm{a}}$ & $75.92 \pm 1.57$ & $69.31 \pm 1.65$ & $61.35 \pm 1.43$ & $54.79 \pm 1.54$ & $49.52 \pm 1.24$ & $44.43 \pm 1.33$ \\
\hline \multicolumn{7}{|l|}{ Zero-order kinetic constants } \\
\hline Regression coefficient $\left(r^{2}\right)$ & 0.9834 & 0.9947 & 0.9892 & 0.9916 & 0.9932 & 0.9875 \\
\hline Proportionality constant $\left(K_{0}\right)$ & 6.3842 & 5.1419 & 3.7874 & 4.3137 & 3.3727 & 2.6908 \\
\hline \multicolumn{7}{|l|}{ First-order kinetic constants } \\
\hline Regression coefficient $\left(r^{2}\right)$ & 0.5863 & 0.7402 & 0.6524 & 0.8446 & 0.8178 & 0.7365 \\
\hline Release rate constant $(K)$ & 0.0413 & 0.0460 & 0.0411 & 0.0485 & 0.0449 & 0.0382 \\
\hline \multicolumn{7}{|l|}{ Hixson-Crowell model kinetic constants } \\
\hline Regression coefficient $\left(r^{2}\right)$ & 0.8993 & 0.9912 & 0.9928 & 0.9903 & $0.997 \mid$ & 0.9914 \\
\hline Surface-volume relation constant $\left(K_{s}\right)$ & 0.3289 & 0.1129 & 0.1008 & 0.0849 & 0.0627 & 0.0488 \\
\hline \multicolumn{7}{|l|}{ Weibull model kinetic constants } \\
\hline Scale parameter $(\alpha)$ & 69.324 & 47.422 & 48.651 & 34.893 & 29.445 & 26.361 \\
\hline Shape parameter $(\beta)$ & 1.8397 & 1.2381 & 1.5977 & 1.0823 & 1.1826 & 1.5970 \\
\hline Location parameter $\left(T_{d}\right)$ & 10.015 & 22.575 & 11.375 & 26.637 & 17.467 & 7.7580 \\
\hline Regression coefficient $\left(r^{2}\right)$ & 0.9428 & 0.9399 & 0.9402 & 0.9310 & 0.9449 & 0.9670 \\
\hline
\end{tabular}

Note: aData presented as mean value \pm standard error, $n=3$.

\section{Percent yield study}

Calculation for percent yield values $(\mathrm{w} / \mathrm{w})$ of all batches were done using equation 2 .

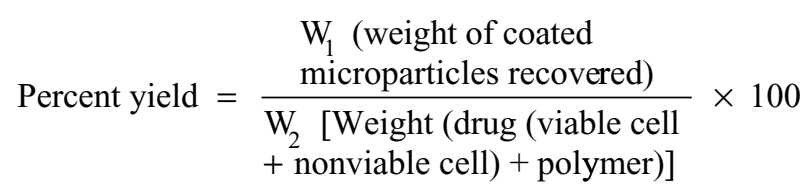

\section{Measurement of viable cell number}

Measurement of viable cells in sample was done using the following methods. ${ }^{22}$

\section{Direct microscopic count using dye exclusion test}

A thoroughly mixed cell suspension $\left(2-5 \times 10^{5}\right.$ cells $\left./ \mathrm{mL}\right)$ was aseptically prepared to $1 \mathrm{~mL}$ with sterile phosphate buffer $\mathrm{pH}$ 6.8. Cell suspension $200 \mu \mathrm{L}$ was mixed thoroughly with $300 \mu \mathrm{L}$ of sterile phosphate buffer $\mathrm{pH} 6.8$ and $500 \mu \mathrm{L}$ of $0.4 \%$ Trypan blue solution in a $1.5 \mathrm{~mL}$ microfuge tube (creating a dilution factor of 5), and kept aside for five minutes. With a coverslip in place, a small volume of the Trypan blue cell suspension was transferred into the chamber of a hemocytometer using a Pasteur pipette and the chamber was allowed to fill up by capillary action to avoid overfilling or underfilling. All the cells (nonviable cells stain blue and viable cells remain opaque) in the $1 \mathrm{~mm}$ center square and the four corner squares were counted under a microscope. The number of viable cells per unit of sample ( $\mathrm{g}$ or $\mathrm{mL}$ ) was calculated using equation 3 . This is a simple and rapid method that provides an approximate result, and was performed in triplicate.

Viable cells $=$ average viable cells count per square $\times$ dilution factor $\times 10^{4}$

Viable plate counts

One gram of sample, alternately one $\mathrm{mL}$ of sample solution, containing $L R$ was transferred aseptically into a presterilized $10 \mathrm{~mL}$ volumetric flask containing $5 \mathrm{~mL}$ of sterile saline $T S$, sonicated at $20 \mathrm{kHz}$ for one minute, and diluted to $10 \mathrm{~mL}$ with sterile saline $T S$. One $\mathrm{mL}$ of this suspension was diluted to $10 \mathrm{~mL}$ in an autoclaved test tube $(25 \mathrm{~mm} \times 150 \mathrm{~mm}$ size $)$ with sterile saline $T S$ and mixed thoroughly. Serial dilution was continued until a suitable dilution was achieved (approximately 100 cell $/ \mathrm{mL}$ ). The final dilution tube was allowed to stand in a water bath at $70^{\circ} \mathrm{C}$ for 30 minutes and was then cooled immediately to about $45^{\circ} \mathrm{C}$. Saline $T S,{ }^{21}$ simulated 
gastric fluid $T S,{ }^{21}$ and simulated intestinal fluid $T S^{21}$ contain inorganic salts but no carbon source, thus $L R$ cells will not proliferate in this media, and remain in a state of stasis until plated on media containing a carbon source. ${ }^{22}$

DeMann Rogosa Sharpe agar medium was liquefied and cooled to $45^{\circ} \mathrm{C}$ on a water bath. One $\mathrm{mL}$ of sample from the heat-treated final dilution tube was transferred into sterile Petri dishes (six per sample), and $15 \mathrm{~mL}$ of molten medium was poured, mixed thoroughly, and then incubated in an inverted position at $40^{\circ} \mathrm{C}$ for 48 hours after solidification.

Six plates were counted and the average count per plate was calculated. The number of cfu per unit ( $\mathrm{mL}$ or $\mathrm{g}$ ) of sample was calculated using equation 4 .

$$
\text { Number of } \mathrm{cfu}=\frac{\begin{array}{c}
\text { Average number of colonies } \\
\text { counted per plate }
\end{array}}{\text { Dilution factor }} \times 100
$$

\section{Entrapment efficiency}

In an aseptic manner, $500 \mathrm{mg}$ of accurately weighed coated microparticles were kept with $25 \mathrm{~mL}$ of sterile simulated intestinal fluid in a hermetically sealed sterile glass vial at $4^{\circ} \mathrm{C} \pm 2^{\circ} \mathrm{C}$ for 24 hours. The dispersion was subjected to a viable plate count (ie, a viable spore count value in $\mathrm{cfu} / \mathrm{g}$ ) and entrapment efficiency was calculated using equation $5 .{ }^{16}$

$$
\begin{aligned}
& \text { Percent entrapment } \\
& \text { efficiency }
\end{aligned}=\frac{\begin{array}{c}
\text { Practical viable spore } \\
\text { count value }
\end{array}}{\begin{array}{c}
\text { Theoretical viable spore } \\
\text { count value }
\end{array}} \times 100
$$

\section{Morphology}

The coated microparticles were mounted on aluminum stubs using double-sided adhesive tape. The stubs were then vacuumcoated with a thin layer of gold and examined with a scanning electron microscope (JSM 5610 LV, Jeol, Tokyo, Japan). ${ }^{23-28}$

\section{Particle size, size distribution, and zeta potential}

The core and coated microparticles were dispersed in deionized water $(\mathrm{pH} 6.8)$ and sonicated at $20 \mathrm{kHz}$ for three minutes to get a homogenous dispersion $(0.5 \% \mathrm{w} / \mathrm{v})$. The dispersions were put into a small-volume disposable zeta cell and subjected to particle size study using photon correlation spectroscopy with an inbuilt Zetasizer (Nano ZS, Malvern Instruments, Worcestershire, UK) at $633 \mathrm{~nm}$ and $25^{\circ} \mathrm{C} \pm 0.1^{\circ} \mathrm{C}$. The electrophoretic mobility measured (in $\mathrm{mm} / \mathrm{sec}$ ) was converted to the zeta potential. ${ }^{16,25-30}$

\section{Flow properties}

The flow properties of the coated microparticles were determined from the result of the study parameters, ie, angle of repose, Carr's index, and the Hausner ratio. ${ }^{16,21}$

\section{In vitro swelling}

An in vitro swelling test of the coated microparticles was conducted in simulated intestinal fluid. The size of the dried microparticles and those after incubation in simulated intestinal fluid for 5 hours were measured using a calibrated optical microscope (CX RIII, Labomed, Ambala, India). Percent swelling value was determined from the diameter of the microparticles at time $t\left(D_{T}\right)$ and initial time $t_{=0}\left(D_{0}\right)$ using equation $6{ }^{16}$

$$
\text { Percent swelling }=\left[D_{T}-D_{0}\right] / D_{0} \times 100
$$

\section{Mucoadhesion}

Following institutional animal ethical committee guidelines, the mucoadhesion affinity of the coated microparticles for intestinal mucosa was assessed by the following methods.

\section{Ex vivo mucoadhesive strength}

A suspension of coated microparticles in simulated intestinal fluid was prepared, and the number of microparticles per $\mathrm{mL}$ $\left(N_{o}\right)$ was determined by optical microscopy. One $\mathrm{mL}$ of this suspension was fed to overnight-fasted albino rats of either gender (in groups of three) which were then sacrificed at hours $0,4,8$, and 12 to isolate their stomach and intestinal regions. The number of microparticles adhering to the stomach and the intestinal regions $\left(N_{S}\right)$ was counted after the regions were cut open longitudinally. Percent adhesive strength value as a measure of ex vivo mucoadhesive strength test was calculated using equation $7 .^{16}$

$$
\text { Percent adhesive strength }=\left[N_{S} / N_{0}\right] \times 100
$$

\section{In vitro washoff test}

A strip of goat intestinal mucosa was mounted on a glass slide, on which a dispersion of accurately weighed microparticles $\left(W_{a}\right)$ in simulated intestinal fluid was uniformly spread and incubated in a desiccator at $90 \%$ relative humidity for 15 minutes. The slide was then placed in a cell at an angle of $45^{\circ}$. Simulated intestinal fluid of $37^{\circ} \mathrm{C} \pm 0.5^{\circ} \mathrm{C}$ was circulated at a rate of $1 \mathrm{~mL} / \mathrm{min}$ to the cell over microparticles adhering to the intestinal mucosa. The weight of washed out microparticles $\left(W_{f}\right)$ in the washings was determined by separation through centrifugation followed by drying at $50^{\circ} \mathrm{C}$. 
The percent mucoadhesion value as a measure of the in vitro washoff test was calculated using equation $8 .{ }^{31}$

$$
\text { Percent mucoadhesion }=\left[\left(W_{a}-W_{f}\right) / W_{\mathrm{a}}\right] \times 100
$$

\section{In vitro release}

In vitro release studies of the coated microparticles were done using a USP basket apparatus (TDT-06T, Electrolab, Mumbai, India) at $37^{\circ} \mathrm{C} \pm 0.5^{\circ} \mathrm{C}$ and $100 \mathrm{rpm}$ containing $900 \mathrm{~mL}$ of sterile dissolution medium, ie, simulated gastric fluid and simulated intestinal fluid with about $1 \mathrm{~g}$ of accurately weighed microparticles contained in the basket (wrapped with 100 mesh nylon cloth) of dissolution apparatus. At predetermined time points, $5 \mathrm{~mL}$ of dissolution medium was withdrawn for up to 14 hours, with immediate replacement of fresh dissolution medium, subjected to viable cell number determination, and the result was expressed as the percentage of viable $L R$ cells released with respect to the practical viable spore count value. ${ }^{16}$

\section{In vitro release kinetics, statistical evaluation, and data fitting}

A mean value of three determinations at each time point was used to fit an in vitro viable cell release profile of all formulation batches to different kinetic models so as to find their release exponents. The mean value of 12 determinations was used to estimate the difference factor $\left(f_{1}\right)$, the similarity factor $\left(f_{2}\right)$, and the two indices of Rescigno $\left(\xi_{1}\right.$ and $\left.\xi_{2}\right) .{ }^{16,32}$ Statistical analysis of percent released data and other data were performed using one-way analysis of variance at a significance level of 5\% $(P<0.05)$. In vitro release kinetic studies, statistical evaluation, data fitting, nonlinear least square curve fitting, simulation, and plotting were performed using Excel software (version 2007, Microsoft Software Inc, Redmond, WA) for determining the parameters of each equation.

\section{In vivo probiotic activity}

The in vivo probiotic activity of the coated microparticles was evaluated using a mouse enterococci stool colonization method, following institutional animal ethical committee guidelines. ${ }^{16}$ One milliliter of coated microparticle dispersion $\left(10^{2} \mathrm{cfu} / \mathrm{mL}\right)$ in simulated intestinal fluid was fed to albino mice in groups of six. Stools were collected at 6-hourly intervals for up to 48 hours and subjected to an enterococci colonization density study.

\section{Accelerated stability}

Following an International Conference on Harmonization guidelines, coated microparticles from all formulation batches were stored under a range of temperature and humidity conditions $\left(30^{\circ} \mathrm{C} \pm 2{ }^{\circ} \mathrm{C} / 65 \% \pm 5 \%\right.$ relative humidity and $40^{\circ} \mathrm{C} \pm 2{ }^{\circ} \mathrm{C} / 75 \% \pm 5 \%$ relative humidity) in a stability analysis chamber (Darwin Chambers Company, St Louis, $\mathrm{MO})$ and in a refrigerator $\left(2^{\circ} \mathrm{C}-8^{\circ} \mathrm{C}\right)$ for an accelerated stability study of up to six months..$^{16,32,33}$

\section{Results and discussion}

The coacervation and phase separation technique described here is a simple, rapid, two-step method, which appears to be suitable for the preparation of coacervate extendedrelease mucoadhesive microparticles loaded with $L R$ cells. It eliminates exposure of $L R$ cells to high temperatures, organic solvents, and mechanical stress, while maintaining their viability during processing. Temperatures above $20^{\circ} \mathrm{C}$ and nonaqueous solvents adversely affect and decrease the viability of $L R$, and this is the reason for commencing developmental processes below $20^{\circ} \mathrm{C}$ in aqueous medium. Hypromellose is soluble in cold water, with solubility in water decreasing with increasing temperature, and it is insoluble in organic solvents like chloroform, dichloromethane, ether, and acetone. ${ }^{19}$ Hypromellose has excellent rate-controlling and mucoadhesion properties. ${ }^{16,17,19}$ Hypromellose phthalate is soluble in aqueous alkali and insoluble in water and propan-2-ol. ${ }^{19}$ Hypromellose was selected as a mucoadhesive polymer and hypromellose phthalate as a coating polymer because of their aforementioned properties, and both are considered to be safe for human consumption. ${ }^{16-19}$ Polysorbate- 80 was incorporated in the formulation as a dispersing agent for homogeneous dispersion of $L R$ cells, and polyethylene glycol 200 was incorporated into the coating solution as a plasticizer to impart plasticity to the coat and to prevent it from splitting and cracking.

$L R$ cells used complied with certificate of analysis specifications, when tested in accordance with the method of analysis provided by the manufacturer. Coating stage percent weight gain values of the formulation batches were in the range of $10.1 \%-13.2 \% \mathrm{w} / \mathrm{w}$.

The percent yield value of the formulation batches ranged from $41.24 \%$ to $58.18 \% \mathrm{w} / \mathrm{w}$, which varied according to the grade of hypromellose used, following the order $\mathrm{E} 5>\mathrm{E} 50>\mathrm{E} 10 \mathrm{M}$, and an increase in the $L R$ to hypromellose ratio decreased the value, and the highest value was observed for the formulation containing E5 (Table 1). A similar trend was also noticed for the entrapment efficiency values that lie between $45.18 \%$ and $64.16 \% \mathrm{cfu} / \mathrm{g}$.

Scanning electron micrographs (Figure 1) of formulations F1, F3, and F5 demonstrate the surface morphology and 


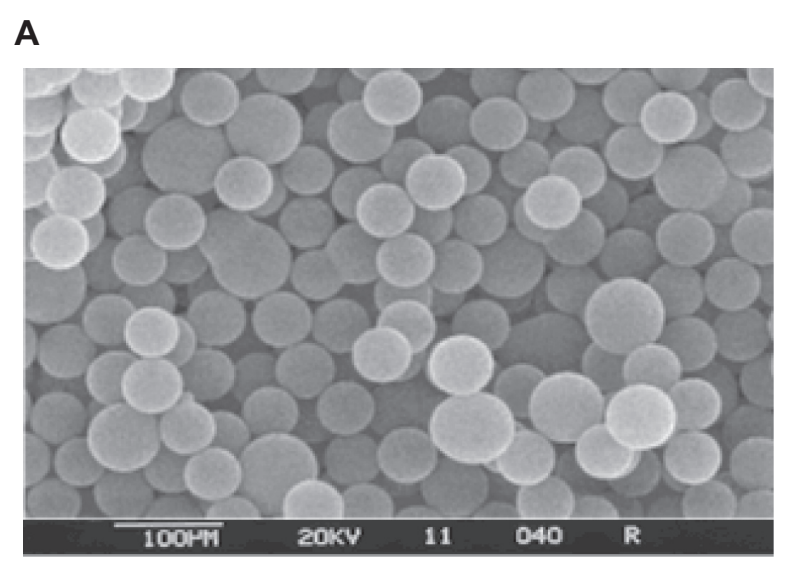

\section{B}

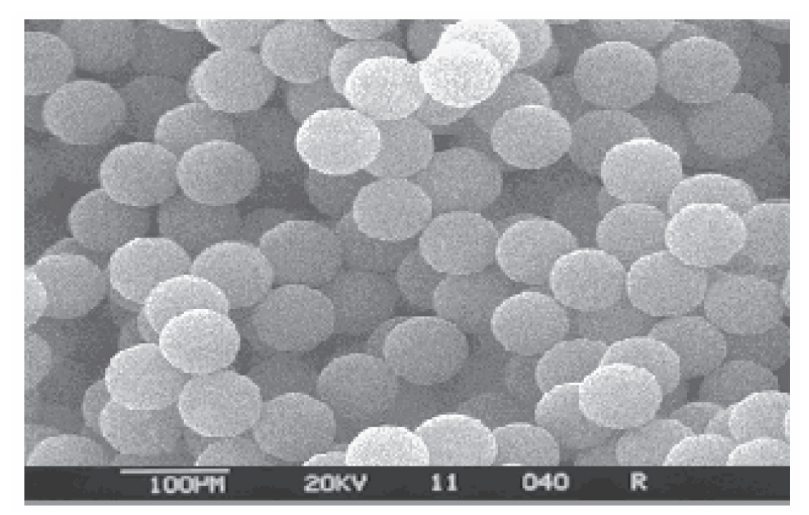

\section{C}

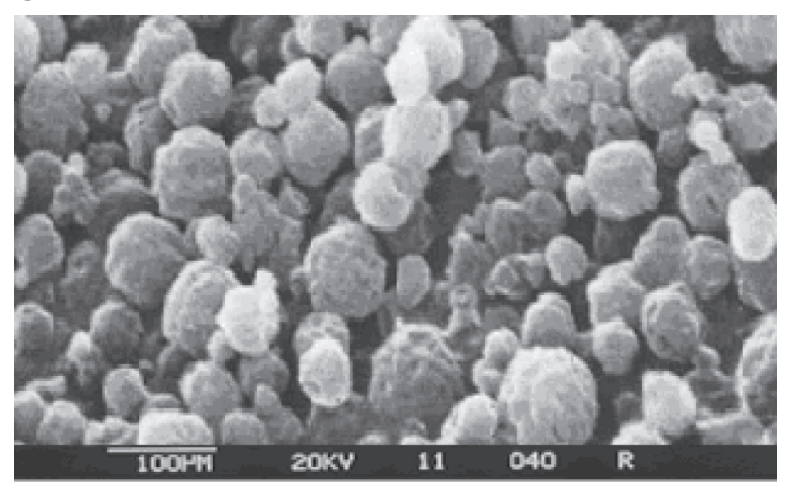

Figure I Scanning electron microscopy photographs of microparticles from formulation batches (A) FI, (B) F3, and (C) F5.

particle size of the coated microparticles. The microparticles of all formulation batches were spherical in shape with a smooth surface, with the exception of microparticles belonging to formulation F5, the surface morphology of which was found to be coarser and shriveled. A coarser and shriveled surface texture in turn will improve adhesion by having stronger mechanical interactions. ${ }^{17}$

The mean particle size values of all formulation batches were in the range of 33.10-49.62 $\mu \mathrm{m}$ (Table 1), which increases with an increase in polymer concentration, while that the grade of hypromellose varied according to mean particle size value in the order of E10 $>$ E50 $>$ E5 M, with the highest value for microparticles prepared with E10 M (Table 1 and Figure 2). A nearly equal zeta potential of around $-19.2 \mathrm{mV}$ was observed for uncoated microparticles of all formulation batches, while coated microparticles had a nearly equal zeta potential at around $-11.5 \mathrm{mV}$. This value is lower than that of the coated microparticles, indicating the presence of hypromellose phthalate on the surface of the microparticles. The zeta potential report for the uncoated microparticles from formulation batch F1 is shown in Figure 3. The flow properties of the formulation batches lie within the passable and very poor ranges.

The percent swelling value of the formulation batches was $0.82 \%-1.38 \%$, and decreases with increasing $L R$ to hypromellose ratio. A variation in the grade of hypromellose also decreased the value in the order of E5 $>$ E50 $>$ E10 M, with the highest value for the microparticles prepared with E5 (Table 1).

The percent adhesive strength of all formulation batches was $42.61 \%-73.36 \%$, which decreases with an increase in the $L R$ to hypromellose ratio (Table 1). A difference in the grade of hypromellose varied the value in the order of E5 $>$ E50 > E10 M, with the highest value seen for E5. A similar trend was also noticed with the percent mucoadhesion value, which ranged between $44.43 \%$ and $75.92 \%$ for all formulation batches. These results indicate that the mucoadhesion properties of the microparticles varied according to the grade of hypromellose and the $L R$ to hypromellose ratio, and that microparticles from formulation batch F1 had the highest mucoadhesion affinity with the intestinal mucosa, so may exhibit high gastric retention time in comparison with the other batches.

The in vitro swelling test result, ex vivo mucoadhesive strength determination, and in vitro washoff test result, as a measure of the mucoadhesion affinity of the microparticles reveals that the mechanism of mucoadhesion initially follows the adsorption theory ${ }^{34,35}$ and subsequently the diffusion theory. ${ }^{35}$

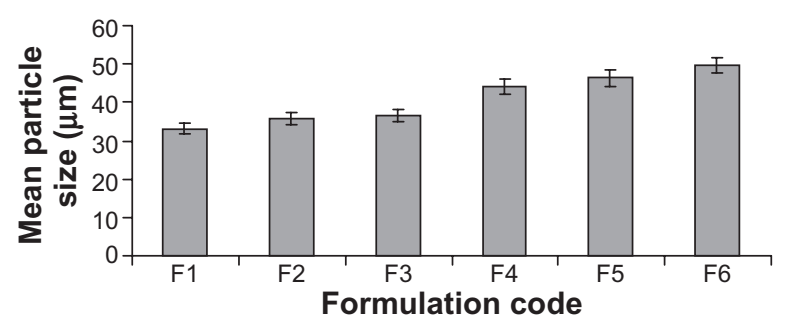

Figure 2 Histogram of mean particle size distribution of all formulation batches. 


\section{Results}

\begin{tabular}{|c|c|c|c|c|}
\hline & & Mean $(\mathrm{mV})$ : & Area $(\%)$ & Width (mV): \\
\hline Zeta potential $(\mathbf{m V}):-19.3$ & Peak 1: & -19.2 & 99.7 & 9.30 \\
\hline Zeta deviation (mV): 9.37 & Peak 2: & 13.7 & 0.3 & 0.00 \\
\hline Conductivity (mS/cm): 0.0885 & Peak 3: & 0.00 & 0.0 & 0.00 \\
\hline
\end{tabular}

\section{Zeta potential distribution}

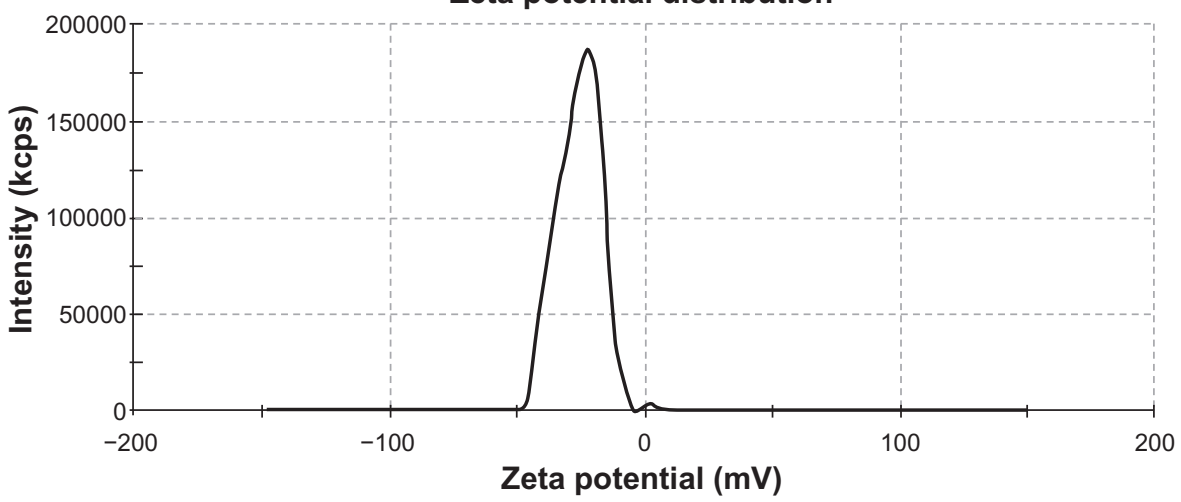

Figure 3 Zeta potential report of uncoated microparticles from formulation batch FI.

The amount of viable $L R$ cells released from the microparticle system in simulated gastric fluid was negligible, but viable $L R$ cell release was almost regulated and extended in simulated intestinal fluid (Figure 4), indicating that enteric coating of microparticles competently protects cell viability at acidic $\mathrm{pH}$, prevents cell release at gastric $\mathrm{pH}$, and releases viable $L R$ cells at intestinal $\mathrm{pH}$.

The results of the in vitro swelling test, ex vivo mucoadhesive strength determination test, in vitro washoff test, and in vitro release profile study demonstrates that, in the intestine ( $\mathrm{pH}>5.0$ ), the coating of the microparticle is dissolved, thereby releasing core microparticles. The liberated core microparticles swell in the intestine, resulting in intimate contact between the microparticles and the mucous membrane. The mucoadhesive chains then penetrate into the crevices of the tissue surface and intermingle with ions in the mucus, with formation of hydrogen bonds between the carboxylic groups of the polymer chains (hypromellose) and mucin molecules, leading to adhesion of the microparticles to the mucous membrane lining the intestinal wall. ${ }^{36-38}$

The kinetic constant and release exponent values of modeldependent approaches (Table 1) show that the mechanism of

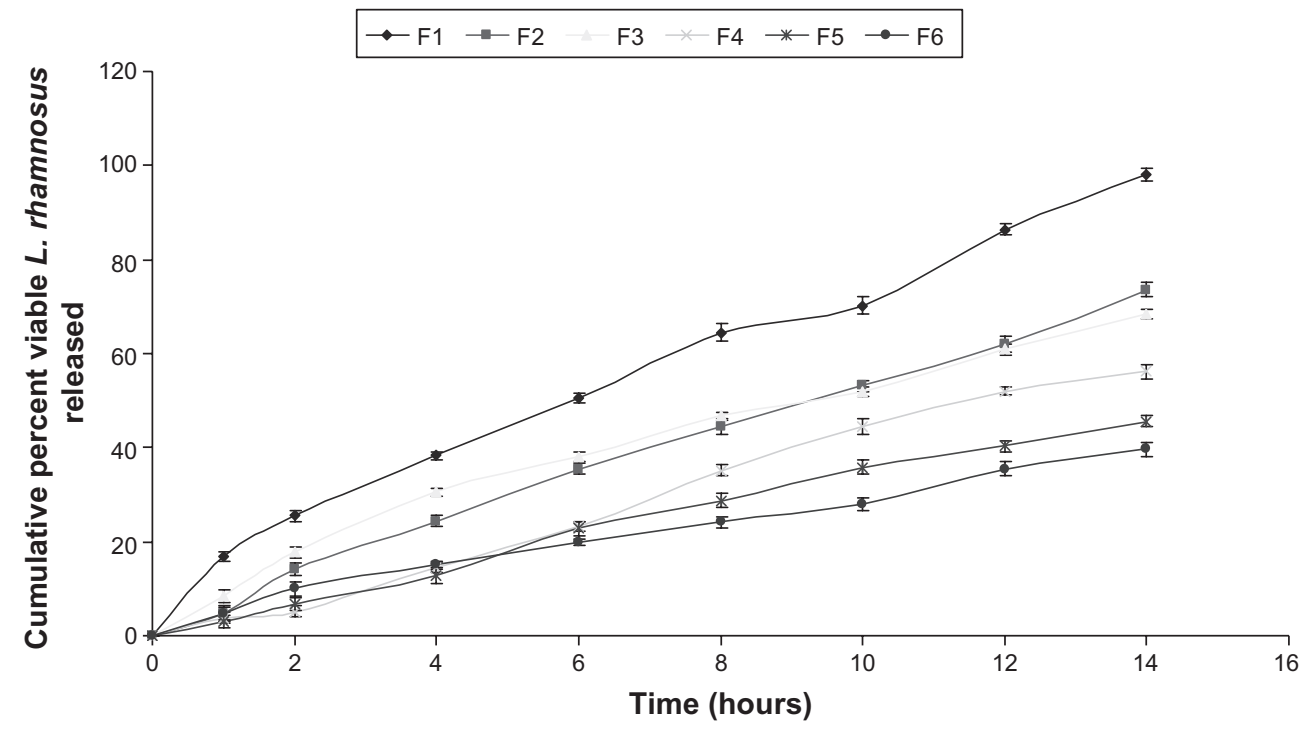

Figure 4 Comparative in vitro release profile of viable Lactobacillus rhamnosus cells from coated microparticles of all formulation batches in simulated intestinal fluid TS, following zero-order kinetics. 
Table 2 Values of the dissimilarity factor $\left(f_{1}\right)$, the similarity factor $\left(f_{2}\right)$ and the two indices of Rescigno $\left(\xi_{1}\right.$ and $\left.\xi_{2}\right)$

\begin{tabular}{lllllllll}
\hline $\begin{array}{l}\text { Model-independent } \\
\text { factors }\end{array}$ & \multicolumn{2}{l}{ Formulation pair } \\
\cline { 2 - 9 } & FI vs F2 & FI vs F3 & FI vs F5 & F2 vs F4 & F2 vs F6 & F3 vs F4 & F5 vs F6 & F4 vs F6 \\
\hline$\xi_{1}$ & 0.102 & 0.137 & 0.328 & 0.133 & 0.299 & 0.098 & 0.070 & 0.173 \\
$\xi_{2}$ & 0.290 & 0.248 & 0.407 & 0.245 & 0.334 & 0.259 & 0.240 & 0.335 \\
$f_{1}$ & 33.00 & 30.78 & 58.00 & 24.64 & 43.00 & 27.00 & 17.00 & 29.84 \\
$f_{2}$ & 36.00 & 36.78 & 24.00 & 50.14 & 36.00 & 48.00 & 68.00 & 48.99 \\
\hline
\end{tabular}

viable $L R$ cell release from coated microparticles follows a zeroorder kinetics model, because the plot of cumulative percent viable cell release versus time was found to be linear, with the highest regression coefficient $\left(r^{2}\right)$ value in comparison with those of the other models. For all formulation batches, the zero-order kinetics model $r^{2}$ value ranged between 0.9834 and 0.9947 . Study of shape parameter values for the Weibull model (Table 1) reveal that the curve is sigmoid or S-shaped, with upward curvature, followed by a turning point as $\beta$ exceeded $1 .^{16,32}$ Study of the location parameter $\left(T_{d}\right)$ for the Weibull model (Table 1) characterizes the time interval necessary to dissolve or release $63.2 \%$ of the drug present in the delivery system ${ }^{16,32}$ and shows that the $T_{d}$ of the formulation batches ranges from 7.7580 to 26.637 hours and the $r^{2}$ value from 0.9310 to 0.9670 .

Model-independent release exponent values are listed in Table 2, and show that for all formulation pairs, ie, the intrapolymer and interpolymer batches, the $\xi_{1}$ values lie between 0.070 and 0.328 , the $\xi_{2}$ values lie between 0.240 and 0.407 , the $f_{1}$ value lies between 17.00 and 58.00, and the $f_{2}$ value lies between 24.00 and 68.00 , indicating dissimilarity in product performance of the formulation batches. ${ }^{16,32}$

A plot of the in vitro viable $L R$ cell release profile following a zero-order kinetics model for all formulation batches in simulated intestinal fluid is shown in Figure 4, and demonstrates that the rate of viable $L R$ cell release from the microparticles decreased significantly with an increase in the $L R$ to polymer ratio, while variation in the grade of hypromellose influenced the release rate from the microparticles, following the order of E10 > E50 > E5 M.

The in vivo probiotic activity evaluation result shows that oral administration of the extended-release mucoadhesive microparticles of $L R$ from all the formulation batches resulted in statistically significant reductions in the density of enterococci colonization in the stool of albino mice up to 24 hours to 36 hours.

The stability study result shows adequate stability of the microparticles under storage conditions of $30^{\circ} \mathrm{C} \pm 2{ }^{\circ} \mathrm{C} / 65 \% \pm 5 \%$ relative humidity, with no change in color and texture or statistically significant decrease in viable $L R$ cell content with respect to the viable spore count, and also confirms that the $L R$ cells were compatible with the excipients used in the formulation. A statistically significant decrease in viable $L R$ cell content was observed with respect to practical viable spore counts at $40^{\circ} \mathrm{C} \pm 2^{\circ} \mathrm{C} / 75 \pm 5 \%$ relative humidity, indicating product instability under these storage conditions.

Extended-release mucoadhesive microparticles from formulation batch F1 was found to be superior to the other prototype formulations because it exhibited the highest values of percent yield, entrapment efficiency, and mucoadhesion affinity, having the ability to protect the viability of $L R$ cells during storage and gastrointestinal transit, and releasing viable $L R$ cells in the gut for an extended period of time, as shown via zero-order kinetics.

\section{Conclusion}

These experimental results suggest that this extended-release microparticulate system loaded with $L R$ cells could be prepared by a conventional coacervation and phase separation technique. It has the potential to deliver viable $L R$ cells to the gut for an extended period of time, while maintaining the viability of $L R$ cells during storage and gastrointestinal transit, and could be viewed as an alternative to conventional dosage forms. However, extensive in vivo studies will be required to establish the use of a coacervate extended-release microparticulate system as an alternative to the conventional dosage form of $L R$.

\section{Acknowledgments}

Thanks are extended to Cipla Ltd for the sample of freeze dried $L R$ cells, to Glenmark Pharmaceuticals Ltd for the sample of HP-50, and to Indoco Remedies Ltd for the samples of Methocel.

\section{Disclosure}

The author reports no conflicts of interest in this work.

\section{References}

1. Sanders ME, Morelli L, Tompkins TA. Sporeformers as human probiotics: Bacillus, Sporolactobacillus, and Brevibacillus. Compr Rev Food Sci Food Saf. 2003;2:101-110.

2. Krasaekoopt W, Bhandari B, Deeth H. Evaluation of encapsulation techniques of probiotics for yoghurt. Int Dairy J. 2003;13:3-13. 
3. Conway PL, Gorbach SL, Goldin BR. Survival of lactic acid bacteria in the human stomach and adhesion to intestinal cells. J Dairy Sci. 1987;70:1-12.

4. Manley KJ, Fraenkel MB, Mayall BC, Power DA. Probiotic treatment of vancomycin-resistant enterococci: a randomised controlled trial. Med J Aust. 2007;186:454-457.

5. Schieszer J. Antibiotic UTI prophylaxis slightly better. Renal and Urology News. November, 2009.

6. Pelto L, Isolauri E, Lilius EM, Nuutila J, Salminen S. Probiotic bacteria down-regulate the milk-induced inflammatory response in milk-hypersensitive subjects but have an immunostimulatory effect in healthy subjects. Clin Exp Allergy. 1998;28:1474-1479.

7. Guandalini S, Pensabene L, Zikri MA, et al. Lactobacillus $G G$ administered in oral rehydration solution to children with acute diarrhea: a multicenter European trial. J Pediatr Gastroenterol Nutr. 2000;30: 54-60.

8. Armuzzi A, Cremonini F, Ojetti V, et al. Effect of Lactobacillus $G G$ supplementation on antibiotic-associated gastrointestinal side effects during Helicobacter pylori eradication therapy: a pilot study. Digestion. 2001;63:1-7.

9. Chandramouli V, Kailasapathy K, Peiris P, Jones M. An improved method of microencapsulation and its evaluation to protect Lactobacillus spp. in simulated gastric conditions. J Microbiol Methods. 2004;56:27-35.

10. O’Riordan K, Andrews D, Buckle K, Conway P. Evaluation of microencapsulation of a Bifidobacterium strain with starch as an approach to prolonging viability during storage. J Appl Microbiol. 2001; 91:1059-1066.

11. Sultana K, Godward G, Reynolds N, Arumugaswamy R, Peiris P, Kailasapathy K. Encapsulation of probiotic bacteria with alginate-starch and evaluation of survival in simulated gastrointestinal conditions and in yoghurt. Int J Food Microbiol. 2000;62:47-55.

12. Gilliand SE, Speck ML. Instability of Lactobacillus acidophilus in yogurt. J Dairy Sci. 1977;60:1394-1398.

13. Lankaputhra WEV, Shah NP. Survival of Lactobacillus acidophilus and Bifidobacterium spp in the presence of acid and bile salts. Cultured Dairy Products J. 1995;30:2-7.

14. Shah NP. Probiotic bacteria: selective enumeration and survival in dairy foods. J Dairy Sci. 2000;83:894-907.

15. Asane GS, Nirmal SA, Rasal KB, Naik AA, Mahadik MS, Rao YM. Polymers for mucoadhesive drug delivery system: a current status. Drug Dev Ind Pharm. 2008;34:1246-1266.

16. Alli SMA. Formulation and evaluation of Bacillus coagulans-loaded hypromellose mucoadhesive microspheres. Int $J$ Nanomedicine. 2011;6:619-629.

17. Chowdary KPR, Rao YS. Mucoadhesive microspheres for controlled drug delivery. Biol Pharm Bull. 2004;27:1717-1724.

18. Li CL, Martini LG, Ford JL, Roberts M. The use of hypromellose in oral drug delivery. J Pharm Pharmacol. 2005;57:533-546.

19. Rowe RC, Sheskey PJ, Owen SC, editors. Handbook of Pharmaceutical Excipients. 5th ed. London, UK: Pharmaceutical Press; 2006.

20. Zhang L, Liu Y, Wu Z, Chen H. Preparation and characterization of coacervate microcapsules for the delivery of antimicrobial oyster peptides. Drug Dev Ind Pharm. 2009;35:369-378.
21. United States Pharmacopoeial Convention. United States Pharmacopoeia-National Formulary (USP-NF) 2008. Rockville, MD: US Pharmacopoeial Convention Inc; 2007.

22. Tortora GJ, Funke BR, Case CL. Microbiology: An Introduction. India: Dorling Kindersley (India) Pvt Ltd; 2006.

23. Mukherjee B, Santra K, Pattnaik G, Ghosh S. Preparation, characterization and in-vitro evaluation of sustained release protein-loaded nanoparticles based on biodegradable polymers. Int J Nanomedicine. 2008;3:487-496.

24. de Azevedo MB, Tasic L, Fattori J, et al. New formulation of an old drug in hypertension treatment: the sustained release of captopril from cyclodextrin nanoparticles. Int J Nanomedicine. 2011;6:1005-1016.

25. Sebak S, Mirzaei M, Malhotra M, Kulamarva A, Prakash S. Human serum albumin nanoparticles as an efficient noscapine drug delivery system for potential use in breast cancer: preparation and in vitro analysis. Int J Nanomedicine. 2010;5:525-532.

26. Azizi E, Namazi A, Haririan I, et al. Release profile and stability evaluation of optimized chitosan/alginate nanoparticles as EGFR antisense vector. Int J Nanomedicine. 2010;5:455-461.

27. Xie S, Zhu L, Dong Z, Wang Y, Wang X, Zhou WZ. Preparation and evaluation of ofloxacin-loaded palmitic acid solid lipid nanoparticles. Int J Nanomedicine. 2011;6:547-555.

28. Hao JF, Fang XS, Zhou YF, et al. Development and optimization of solid lipid nanoparticle formulation for ophthalmic delivery of chloramphenicol using a Box-Behnken design. Int J Nanomedicine. 2011;6:683-692.

29. Thakral NK, Ray AR, Bar-Shalom D, Eriksson AH, Majumdar DK. The quest for targeted delivery in colon cancer: mucoadhesive valdecoxib microsphere. Int J Nanomedicine. 2011;6:1057-1068.

30. Guan P, LuY, Qi J, et al. Enhanced oral bioavailability of cyclosporine A by liposomes containing a bile salt. Int J Nanomedicine. 2011;6:965-974.

31. Venkateswaramurthy N, Sambathkumar R, Perumal P. Clarithromycin mucoadhesive microspheres for anti Helicobacter pylori therapy: Formulation and in-vitro evaluation. Int J Current Pharm Res. 2010;2:24-27.

32. Alli SMA, Samanta A, Mukherjee B, Ali SMA, Dehury G, Kanungo S. Hydrophilic polymeric matrix tablet for sustained delivery of levofloxacin. Int J Pharm Sci Tech. 2010;5:40-55.

33. Sahana B, Santra K, Basu S, Mukherjee B. Development of biodegradable polymer based tamoxifen citrate loaded nanoparticles and effect of some manufacturing process parameters on them: a physicochemical and in-vitro evaluation. Int J Nanomedicine. 2010;5:621-630.

34. Mikos AG, Peppas NA. Measurement of the surface tension of mucin solutions. Int J Pharm. 1989;53:1-5.

35. Jasti B, Li X, Cleary G. Recent advances in mucoadhesive drug delivery systems. Business Briefing: Pharmtech. 2003:194-197.

36. Duchene D, Touchard F, Peppas NA. Pharmaceutical and medical aspects of bioadhesive systems for drug administration. Drug Dev Ind Pharm. 1988;14:283-318

37. Leung SHS, Robinson JR. Polymer structure features contributing to mucoadhesion II. J Control Release. 1990;12:187-194.

38. Chickering DE, Mathiowitz E. Fundamentals of bioadhesion. In: Mathiowitz E, Chickering DE, Lehr CM, editors. Novel Approaches and Development. New York, NY: Marcel Dekker; 1999.
International Journal of Nanomedicine

\section{Publish your work in this journal}

The International Journal of Nanomedicine is an international, peerreviewed journal focusing on the application of nanotechnology in diagnostics, therapeutics, and drug delivery systems throughou the biomedical field. This journal is indexed on PubMed Central,

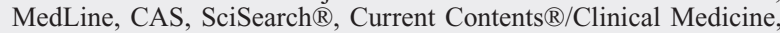

\section{Dovepress}

Journal Citation Reports/Science Edition, EMBase, Scopus and the Elsevier Bibliographic databases. The manuscript management system is completely online and includes a very quick and fair peer-review system, which is all easy to use. Visit http://www.dovepress.com/ testimonials.php to read real quotes from published authors. 